\title{
LMNA-related cardiocutaneous progeria syndrome
}

INSERM

\section{Source}

INSERM. (1999). Orphanet: an online rare disease and orphan drug data base. LMNArelated cardiocutaneous progeria syndrome. ORPHA:363618

LMNA-related cardiocutaneous progeria syndrome is a rare, genetic, premature aging syndrome characterized by adulthood-onset cutaneous manifestations that result in a prematurely aged appearance (i.e. premature thinning and graying of scalp hair, loss of subcutaneous fat, tightening of skin) associated with prominent cardiovascular manifestations, such as accelerated atherosclerosis, calcific valve disease, and cardiomyopathy. Patients present loss of eyebrows and eyelashes in childhood and have a predisposition to develop malignancies. 